\title{
Caracterização do processo de vinificação do vinho de mesa das cantinas de Santa Teresa, Espírito Santo
}

\author{
Characterization of table wine making process in cateens of Santa Teresa, Espírito \\ Santo
}

\author{
Marcio Vinícius Ferreira de Sousa ${ }^{1}$; Marcus Vinicius Sandoval Paixão ${ }^{1 *}$, Juliana Abreu \\ Rezende $^{2}$, Tiago Lopes dos Santos ${ }^{1}$, Jéssica Folli Monteiro ${ }^{1}$, Klaus Henrique Ratunde ${ }^{1}$
}

\begin{abstract}
RESUMO
Na região serrana do Espírito Santo a vitivinicultura é praticada desde 1875 pelos imigrantes italianos. Considerando a importância da vitivinicultura para Santa Teresa e a pouca disponibilidade de informações existentes sobre as tecnologias enológicas empregadas na elaboração do vinho, o presente trabalho foi realizado com o objetivo de caracterizar o processo de produção do vinho de mesa nas cantinas de Santa Teresa. Oito foram selecionadas para participarem da pesquisa de campo. Os responsáveis pelas cantinas responderam a um questionário descritivo-quantitativo em entrevistas individuais, no qual foram caracterizadas todas as etapas de vinificação, bem como algumas perguntas sobre o cultivo e a colheita da uva. Ficou demonstrado na pesquisa que as técnicas enológicas utilizadas nas cantinas foram adequadas na maioria dos casos durante todas as etapas de elaboração dos vinhos, bem como no cultivo e na colheita das uvas. Algumas medidas para o aprimoramento da qualidade e produção poderão ser adotadas, como a aquisição de caixas de polietileno de $20 \mathrm{~kg}$; a realização da segunda sulfitagem; a utilização de levedura selecionada e enzima; o uso de tanque de fermentação de polipropileno ou inox; a aquisição de garrafas padronizadas; a rotulação dos vinhos e a realização de análises físico-químicas e sensoriais nos vinhos.
\end{abstract}

Palavras chave: Vinho de mesa, vinificação, cantina.

\section{ABSTRACT}

In the mountainous region of the Espírito Santo State viticulture is practiced since 1875 by Italian immigrants. Given the importance of viticulture to Santa Teresa, and the limited information available on enological technologies employed in winemaking, we performed this study in order to characterize the production process of table wine in the canteens of Santa Teresa. Eight were selected to participate in the field research. Canteens managers completed a descriptive-quantitative questionnaire in individual interviews, which characterized all stages of winemaking, as well as some questions about the cultivation and harvesting of grapes. It was demonstrated that enological techniques employed were adequate in most cases during all stages of winemaking, as well as in the grapes growing and harvesting. Some actions to improve the quality and production yield should be taken as the acquisition of polyethylene tanks of $20 \mathrm{~kg}$, the organization of the 2nd sulphitation, use of selected yeast and enzyme, using fermentation tank polypropylene or stainless the acquisition of standard bottles and the realization of physicochemical and sensory analysis in wines.

Index terms: Table wine, winemaking, canteens.

\footnotetext{
${ }^{1}$ Instituto Federal do Espírito Santo

${ }^{2}$ Universidade Estadual Darçi Ribeiro

*E-mail: mvspaixao@gmail.com
} 


\section{INTRODUÇÃO}

As primeiras variedades de uvas introduzidas no Brasil pelos portugueses eram cultivares de uvas finas (Vitis vinifera L.) europeias. A viticultura brasileira somente se consolidou em meados do século XIX, com a introdução da cultivar americana Isabel (Vitis labrusca L.), pelos imigrantes italianos (CAMARGO et al., 2010). Vinho tinto e seus derivados são produzidos no Brasil com cultivares de uvas americanas e híbridas de espécies de V. labrusca L., que são responsáveis por mais de $85 \%$ do volume de produção de uvas no Brasil (NIXDORF; HERMOSÍ-GUTIÉRREZ, 2010).

Na região serrana do Espírito Santo a vitivinicultura é praticada desde 1875 pelos imigrantes italianos. Na década de 1940, o Ministério da Agricultura implantou no município de Domingos Martins uma estação experimental para fomentar a vitivinicultura regional, principalmente nos municípios de Venda Nova do Imigrante e Santa Teresa (PROTAS; CAMARGO, 2011).

Em 2005, os produtores de uva e vinho de Santa Teresa, ES criaram a Associação dos Produtores de Uva e Vinho Teresense (APRUVIT), com o apoio do Serviço Brasileiro de Apoio às Micro e Pequenas Empresas (SEBRAE-ES), do Instituto Capixaba de Pesquisa, Assistência Técnica e Extensão Rural (INCAPER) e da Prefeitura Municipal de Santa Teresa. A APRUVIT implantou ações para o desenvolvimento tecnológico para seus associados por intermédio de consultorias, visitas técnicas, cursos e treinamentos (PROTAS; CAMARGO, 2011).

O vinho de mesa de americanas é elaborado com uvas da variedade americana e, ou, híbridas, podendo conter vinhos de variedades viníferas. O vinho deve possuir entre 8,6 a $14 \%$ v/v, à $20{ }^{\circ} \mathrm{C}$ (BRASIL, 2004). A vinificação é o conjunto de procedimentos e processos empregados para a transformação da uva madura em vinho. As principais etapas da vinificação clássica em tinto são: colheita; recepção e análise da uva; desengace/ esmagamento; sulfitagem; adição de enzimas; inoculação de levedura; maceração; fermentação alcoólica; chaptalização; descuba/prensagem; trasfegas/atesto; colagem; e engarrafamento e arrolhamento (GUERRA, 2010).

Considerando a importância do setor vitivinícola para o município e a pouca disponibilidade de informações existentes sobre as tecnologias enológicas empregadas na elaboração do vinho, o presente trabalho foi realizado com o objetivo de caracterizar o processo de produção do vinho tinto de mesa nas cantinas de Santa Teresa, ES. 


\section{MATERIAL E MÉTODOS}

Contatos iniciais foram realizados em setembro de 2010 junto a APRUVIT com seus associados em reunião na sede da entidade com a presença dos principais produtores de vinhos de mesa do município, apresentando os objetivos e convidando-os a participarem da pesquisa. Todos os responsáveis pelas cantinas demonstraram interesse em participar, sendo que, de um total de nove, oito confirmaram a participação. As etapas envolvidas na pesquisa e aceitas pelos produtores foram: cultivo; colheita; variedade; tipo de vinho produzido; volume de produção em L. $\mathrm{ano}^{-1}$; e disponibilidade das cantinas para visitas técnicas.

$\mathrm{Na}$ caracterização do processo de produção dos vinhos de mesa das cantinas de Santa Teresa, ES, os estabelecimentos selecionados receberam a visita em outubro de 2010. Nesta ocasião, cada responsável pela produção das cantinas respondeu a um questionário descritivo-quantitativo realizado sob a forma de entrevista individual, que foi elaborado e aplicado com base nas referências de Rosier (1995) e Rizzon et al. (2003). Dos dados levantados na entrevista foram obtidas informações de todas as etapas de processamento do vinho de mesa e algumas questões sobre o cultivo e a colheita da uva.

\section{RESULTADOS E DISCUSSÃO}

A caracterização das cantinas em relação ao cultivo e à colheita das uvas está indicada na Tabela 1. Do total de oito cantinas pesquisadas, quatro delas elaboram o vinho somente a partir de suas próprias uvas, tendo, portanto, o controle sobre sua matériaprima. As outras cantinas utilizam na vinificação uvas de outros produtores de Santa Teresa, ES, não havendo, portanto, nenhum controle sobre o manejo realizado no cultivo da uva. Para o vinho ter qualidade e ser seguro ao consumidor, há a necessidade de monitorar o resíduo de pesticidas e de metais na colheita da uva (CHRISTAKI; TZIA, 2002). Todos os produtores realizam anualmente a análise físico-química do solo, prática cultural que associada a outros fatores resulta na obtenção de uvas maduras, sadias e capazes de proporcionar qualidade ao vinho (REGINA et al., 2006).

Todas as cantinas avaliadas realizam a colheita com tempo seco, após o teor de ${ }^{\circ}$ Babo ser considerado satisfatório (Tabela 1). Esta medição permite ao produtor determinar precariamente o ponto ideal de colheita da uva, pois a uva deve ser colhida 
considerando além do teor de ${ }^{\circ}$ Babo, a acidez total, o $\mathrm{pH}$ e os polifenóis (GUERRA, 2010). As cantinas que produzem sua própria uva e as que adquirem de fornecedores realizam a colheita manual (Tabela 1). Este tipo de colheita preserva mais a integridade física da uva em relação à colheita mecânica (MOTA et al., 2006). A colheita mecânica só se justifica quando o plantio for superior à 140 ha (TRONCOSO et al., 2002), não sendo esta a realidade da vitivinicultura em Santa Teresa, ES. Todas as cantinas utilizam caixas de polietileno de 8 e $20 \mathrm{~kg}$ com furos na colheita e no transporte das uvas até as cantinas (Tabela 1). Esta prática é adequada, pois permite que as caixas sejam empilhadas sem danificar a uva e ser de fácil higienização (ROSIER, 1995).

Tabela 1 - Caracterização das cantinas em relação ao cultivo e colheita das uvas $(\mathrm{n}=8)$

\begin{tabular}{|c|c|}
\hline Caracterização & Cantinas \\
\hline Produz as próprias uvas & 4 \\
\hline Fornecedores não são controlados & 4 \\
\hline $\begin{array}{l}\text { Realizam análise de solo (físico-química) } \\
\text { anualmente }\end{array}$ & 8 \\
\hline $\begin{array}{l}\text { Quando realiza a colheita após o }{ }^{\circ} \text { Babo ser } \\
\text { considerado satisfatório: }\end{array}$ & 8 \\
\hline Colheita manual & 8 \\
\hline $\begin{array}{l}\text { Capacidade das caixas de polietileno ( } 8 \text { e } 20 \mathrm{~kg} \text { ), } \\
\text { com furos }\end{array}$ & 8 \\
\hline
\end{tabular}

Fonte: Dados da pesquisa

A Tabela 2 apresenta as técnicas enológicas utilizadas nas cantinas em relação ao transporte e à recepção das uvas. Das oito cantinas avaliadas, sete realizam a separação das bagas ruins no momento da recepção das uvas. Estas operações possibilitam aos produtores obterem vinho de melhor qualidade sensorial e uma diminuição na sulfitagem. Segundo Mota et al. (2006), a seleção da uva colhida permite a vinificação de lotes semelhantes, sem problemas de podridão ou de desuniformidade na maturação.

Todas as cantinas (Tabela 2) pesam as uvas na recepção; esta operação possibilita estimar o volume de vinho a ser elaborado (em média, 65 a $70 \%$ do peso total da uva), e realizar os cálculos dos insumos a serem utilizados na vinificação (sulfitagem, chaptalização, inoculação de levedura, enzima e colagem) (ROSIER, 1995; RIZZON, et al., 2003). Quanto à medição do teor de ${ }^{\circ}$ Babo da uva, apenas uma das cantinas não realiza esta análise. O grau glucométrico deve ser determinado para fins de cálculo do potencial 
alcoólico e de eventuais correções do mosto (GUERRA, 2010).

Conforme a Tabela 2, nenhuma das cantinas utiliza o transporte refrigerado das uvas às cantinas. A colheita é realizada na época mais quente de Santa Teresa, ES, o que pode acarretar o desenvolvimento e a ação de bactérias acéticas, prejudicando a preservação e a qualidade do vinho (MOTA et al., 2006). Os produtores contornam estes problemas com a colheita nas primeiras horas da manhã e o envio imediato das uvas para a vinificação.

Das cantinas pesquisadas nenhuma realiza a determinação da acidez total na uva (Tabela 2). Os produtores e as cantinas desconhecem que a medição da acidez total é um fator importante na determinação do ponto ideal de colheita. A determinação da acidez total permite efetuar correções no mosto, assegurando com isto uma fermentação normal, um sabor mais agradável e uma cor mais viva nos vinhos, bem como a proteção contra microrganismos indesejáveis (RIBÉREAU-GAYON et al., 2003).

Segundo os dados apresentados na Tabela 2, todas as cantinas realizam o desengace e esmagamento da uva. As cantinas pesquisadas possuem desengaçadoraesmagadora de variadas capacidades, de acordo com a quantidade de vinho elaborado na cantina. Para Guerra (2010), na vinificação em tinto, o desengace e o esmagamento podem ser realizados simultaneamente, por máquina, denominada desengaçadoraesmagadora, dotadas de regulagens que permitem evitar a quebra dos engaços, fator fundamental para a qualidade aromática e gustativa do vinho tinto.

Tabela 2 - Técnicas enológicas utilizadas nas cantinas em relação ao transporte e recepção das uvas $(n=8)$

\begin{tabular}{lc}
\hline \multicolumn{1}{c}{ Técnicas enológicas } & Cantinas \\
\hline Realizam separação das bagas ruins & 7 \\
Realizam pesagem da uva & 8 \\
Realizam o transporte refrigerado $\left({ }^{\circ} \mathrm{C}\right)$ das uvas & - \\
Realizam medição do ${ }^{\circ}$ Babo da uva & 7 \\
Realizam medição da acidez da uva & - \\
Realizam desengace/esmagamento da uva & 8 \\
\hline
\end{tabular}

Fonte: Dados da pesquisa

Os resultados dispostos na Tabela 3 mostram que apenas uma cantina utiliza tanque de fermentação de aço inoxidável para realizar a maceração/fermentação do mosto, sendo a cantina mais tecnificada. Quatro cantinas utilizam recipientes de 
polipropileno (aberto), as demais cantinas utilizam recipientes de polietileno (caixa d'água: aberto), em virtude do seu baixo custo e fácil manejo; contudo, estes recipientes são de difícil higienização.

Obsrva-se na Tabela 3, que todas as cantinas controlam a temperatura com a remontagem. Os produtores relatam que o monitoramento da temperatura nos tanques de fermentação é realizado com termômetro específico para este fim. A despeito deste controle, não há nenhum sistema de refrigeração dos tanques de fermentação das cantinas. Quando não se dispõe de sistema de refrigeração, o uso de remontagens é uma excelente forma de diminuir as elevadas temperaturas ocasionadas pelo processo de fermentação. Nesta faixa, as leveduras demonstram menor sensibilidade aos efeitos tóxicos do álcool, favorecendo seu crescimento (RIZZON et al., 1996). A temperatura ótima de fermentação para vinhos tintos situa-se entre 20 e $26{ }^{\circ} \mathrm{C}$, o que facilita a extração de compostos fenólicos, responsáveis pela cor e estrutura destes vinhos (GUERRA; BARNABÉ, 2005).

Dos estabelecimentos avaliados (Tabela 3), o tempo de maceração do mosto foi adequado para vinhos de consumo imediato, como no caso das cantinas de Santa Teresa, ES, situando-se entre três a sete dias. O tempo de maceração varia em função do tipo de vinho a elaborar. De acordo com Guerra e Barnabé (2005), na produção de vinhos tintos para consumo imediato, a maceração varia de três a seis dias. Com o tempo de maceração de cinco a sete dias para a produção de vinho tinto jovem, segundo Rizzon et al. (2003), é possível elaborar uma bebida com certa estrutura, boa intensidade de cor e sem perder a característica de frutado.

Tabela 3 - Caracterização dos tanques de fermentação $(n=8)$

\begin{tabular}{ll}
\hline \multicolumn{1}{c}{ Equipamento } & Cantinas \\
\hline Recipiente e material: & \\
- Tanque de polietileno (caixa d'água) aberto & 3 \\
- Tanque de polipropileno aberto & 4 \\
- Tanque de aço Inoxidável fechado & 1 \\
- Tempo de maceração três a sete dias & 8 \\
- Temperatura controlada com a remontagem & 8 \\
\hline
\end{tabular}

Fonte: Dados da pesquisa

A caracterização das cantinas em relação à sulfitagem está descrita na Tabela 4. Todas as cantinas realizam a primeira sulfitagem no mosto. Assim que a uva é esmagada, é essencial proteger o mosto contra a ação do oxigênio e da contaminação microbiana. 
Todos os produtores reconhecem a importância da realização desta prática para evitar, segundo eles, "o vinho avinagrar". A quantidade de metabissulfito de potássio recomendada na primeira e segunda sulfitagem é de 15 a 20 g.h L $\mathrm{h}^{-1}$ e de 8 a 10 g.h L L respectivamente, no mosto (ROSIER, 1995; GUERRA; BARNABÉ, 2005). Ainda, na Tabela 4, pode-se observar que somente uma cantina realiza a sulfitagem acima da dosagem recomendada, o que pode ocasionar inconvenientes no vinho, como retardar a maturação; a fermentação; diminuir a intensidade de cor; provocar o aparecimento de odor desagradável; e prejudicar a fermentação malolática (ROSIER, 1995; GUERRA; BARNABÉ, 2005). Quanto à segunda sulfitagem, apenas a cantina mais tecnificada realiza esta prática, de acordo com as recomendações. Esta técnica enológica foi repassada aos produtores pelos pesquisadores da Embrapa Uva e Vinho em curso de capacitação realizado em Santa Teresa, ES. O produtor que utiliza a segunda sulfitagem não determina $\mathrm{o} \mathrm{SO}_{2}$ residual, etapa importante para efetuar a correção, mantendo o teor entre 25 a $30 \mathrm{mg} \cdot \mathrm{L}^{-1}$. A legislação brasileira permite a dose máxima de $35 \mathrm{~g} . h \mathrm{~L}^{-1}$ de $\mathrm{SO}_{2}$ no vinho (BRASIL, 1988).

Tabela 4 - Caracterização das cantinas em relação à sulfitagem $(n=8)$

\begin{tabular}{ll}
\hline \multicolumn{1}{c}{ Técnicas enológicas } & Cantinas \\
\hline $\begin{array}{l}\text { Realizam a primeira sulfitagem com } \\
\text { metabissulfito de potássio }\end{array}$ & 8 \\
Quantidade adicionada: $15 \mathrm{~g} \cdot \mathrm{h} \mathrm{L}{ }^{-1}$ & 5 \\
Quantidade adicionada: $20 \mathrm{~g} \cdot \mathrm{h} \mathrm{L}^{-1}$ & 2 \\
Quantidade adicionada: $25 \mathrm{~g} \cdot \mathrm{h} \mathrm{L} \mathrm{L}^{-1}$ & 1 \\
$\begin{array}{l}\text { Realizam a segunda sulfitagem com } \\
\text { metabissulfito de potássio: } 10 \mathrm{~g} \cdot \mathrm{h} \mathrm{L}\end{array}$ & 1 \\
\hline
\end{tabular}

Fonte: Dados da pesquisa

Os resultados da caracterização da inoculação de levedura, adição de enzima pectinolítica e remontagem estão indicados na Tabela 5. Das oito cantinas avaliadas duas realizam a fermentação espontânea do mosto. Os produtores relatam que não utilizam a levedura selecionada por desconhecimento e por não saberem de seus benefícios. As vantagens do uso de leveduras selecionadas são: rápida multiplicação; alta conversão de açúcares em etanol; tolerância a elevados teores de $\mathrm{SO}_{2}$; baixa produção de metanol e alcoóis superiores; e capacidade de produção de aromas típicos (GUERRA, 2010). As cantinas que adicionam leveduras selecionadas na fermentação do mosto seguem todas as recomendações do fabricante (Tabela 5). Os dados apresentados na Tabela 5 indicam 
que nenhum dos produtores pesquisados utiliza enzima pectinolítica na vinificação. $\mathrm{Na}$ entrevista foi destacado pelos produtores o desconhecimento e sua importância na vinificação. Amorim et al. (2006) enfatizam que o uso de enzimas pectinolíticas possuem as vantagens de facilitar a extração de polifenóis, em especial as antocianinas, realçando a cor vermelha mais intensa do vinho tinto. A remontagem é realizada por todas as cantinas e em quantidade adequada (Tabela 5). Os produtores utilizam na remontagem do vinho pás de polietileno, tendo como objetivos controlar a temperatura (26 a $\left.30{ }^{\circ} \mathrm{C}\right) \mathrm{da}$ fermentação, e deixar o bagaço em contato por mais tempo com o mosto, para extrair "cor" no vinho tinto. Na prática, trata-se de uma maneira de homogeneizar as fases sólida e líquida, dado que a fase sólida (bagaço) concentra-se na parte superior do tanque de fermentação (GUERRA, 2010). Em qualquer que seja o sistema de remontagem (manual ou mecânico) utilizado na vinificação em tinto, o número de remontagens diárias varia de quatro a seis, o que permite a extração seletiva dos compostos das partes sólidas das uvas (GUERRA; BARNABÉ, 2005).

Tabela 5 - Caracterização da inoculação de levedura, adição de enzima pectinolítica e remontagem $(n=8)$

\begin{tabular}{lc}
\hline Técnicas enológicas & Cantinas \\
\hline Adicionam levedura selecionada & 6 \\
Quantidade adicionada: $20 \mathrm{~g} \cdot \mathrm{hL}^{-1}$ & 6 \\
Utilizam as recomendações do fabricante sobre o & 6 \\
modo de utilização: & - \\
Utilizam enzima pectinolítica & 8 \\
Realizam a remontagem & 8 \\
Quantas são realizadas diariamente: 4 a 5 por dia & \\
\hline
\end{tabular}

Fonte: Dados da pesquisa

A Tabela 6 apresenta a caracterização da chaptalização, descuba e prensagem realizada pelas cantinas. Das cantinas entrevistadas, cinco utilizam o açúcar cristal na etapa de maceração e três adicionam o açúcar cristal após a prensagem (Tabela 6). Na colheita da safra de verão de 2010 houve um excesso de chuva, o que ocasionou um baixo teor glucométrico das uvas. Segundo Brasil (2011), a chaptalização é considerada lícita e objetiva, para corrigir a deficiência de açúcar do mosto em virtude das condições desfavoráveis de maturação das uvas destinadas à vinificação. A sacarose é o açúcar recomendado para efetuar a chaptalização do vinho Isabel, da serra gaúcha (RIZZON; MIELE, 2005). 
Os produtores que adicionam açúcar depois da descuba (Tabela 6) entendem que com este procedimento haverá menor perda de açúcar, quando comparado aos que adicionam na maceração. As uvas vinificadas nas cantinas estavam com baixo teor de açúcar; portanto, a correção foi ao máximo permitida pela legislação brasileira, que é de $3{ }^{\circ} \mathrm{GL}$. Na obtenção de cada $1{ }^{\circ} \mathrm{GL}$ de álcool, são necessários $1,8 \mathrm{~kg}$.h L L ${ }^{-1}$ de açúcar no mosto (GUERRA, 2010). As cantinas utilizaram 5,4 kg.h L ${ }^{-1}$ de açúcar na correção do mosto. Guerra (2010) recomenda a chaptalização em duas etapas: metade na maceração e metade após a descuba, quando a quantidade de açúcar adicionada for superior aos 4 kg.h L ${ }^{-1}$.

Das cantinas entrevistadas (Tabela 6), todas realizam a prensagem do bagaço depois da descuba. Os produtores prensam o vinho com os objetivos de aumentar o rendimento (10 a $15 \%$ ) e misturar os vinhos "gota" e "prensa". Todas as cantinas utilizam prensa, sendo cinco vertical manual, duas de madeira e uma pneumática (Tabela 6). As cantinas de menor produção por questão de custo utilizam prensas de madeira. A maioria das cantinas utiliza a descontínua vertical manual de força hidráulica com capacidade de prensar $500 \mathrm{~kg}$. Somente um dos produtores utiliza a prensa pneumática e justifica seu uso pela sua maior produção de vinho. O vinho prensa pode ser misturado, o que possibilita a estas cantinas ganhos na qualidade sensorial de seus vinhos e rendimentos de mosto mais elevados (RIZZON et al., 2003; GUERRA; BARNABÉ, 2005).

Tabela 6 - Caracterização da chaptalização, descuba e prensagem $(n=8)$

\begin{tabular}{lll}
\hline Técnicas enológicas & Cantinas \\
\hline Adicionado açúcar cristal uma só vez (maceração) & 5 & \\
Adicionado açúcar cristal uma só vez (após prensagem) & 3 \\
Realizam a descuba com prensa & 8 \\
Descontínua vertical manual & 5 \\
Madeira & 2 \\
Vertical hidropneumática & 1 \\
\hline
\end{tabular}

Fonte: Dados da pesquisa

Na Tabela 7 encontram-se os resultados da caracterização da fermentação em sua fase lenta. Todas as cantinas utilizam o tanque de fermentação com a colocação do botoque hidráulico. Esta técnica permite a saída do $\mathrm{CO}_{2}$ e evita a entrada de ar, evitando o avinagramento do vinho pela ação de bactérias e leveduras indesejáveis na fermentação 
(GUERRA; BARNABÉ, 2005). O tempo de duração da fermentação (fase lenta) em todas as cantinas está de acordo com a literatura, variando de 20 a 30 dias.

Tabela 7 - Caracterização da fermentação (fase lenta) $(n=8)$

\begin{tabular}{lc}
\hline \multicolumn{1}{c}{ Técnica enológica } & Cantinas \\
\hline Tanque de fermentação fechado com batoque hidráulico & 8 \\
Tempo de fermentação (fase lenta) & - \\
20 a 30 dias & 3 \\
30 dias & 5 \\
\hline
\end{tabular}

Fonte: Dados da pesquisa

A caracterização da trasfega e do atesto são apresentados na Tabela 8. Todas as cantinas realizam as trasfegas na quantidade e no tempo adequado. Dependendo do nível tecnológico das cantinas, as trasfegas são realizadas com o auxílio de pequenas bombas, por gravidade (mangueira), ou por bomba de aço inox, deixando ao fundo a borra depositada. A trasfega é fundamental na obtenção de vinhos sem defeitos no odor, aroma e com boa limpidez (RIZZON et al., 1994; ROSIER, 1995). O atesto é realizado em todas as cantinas (Tabela 8) sempre após cada trasfega. O vinho sem atesto pode oxidar e, ou, criar condições favoráveis ao desenvolvimento, principalmente de bactérias acéticas (GUERRA; BARNABÉ, 2005).

Tabela 8 - Caracterização da trasfega e atesto $(n=8)$

\begin{tabular}{|c|c|}
\hline Técnicas enológicas & Cantinas \\
\hline A $1^{a}$ trasfega é realizada 15 dias após fermentação (fase lenta) & 8 \\
\hline A $2^{a}$ trasfega é realizada 30 dias após fermentação (fase lenta) & 8 \\
\hline A 3 a trasfega é realizada 30 dias após $2^{a}$ trasfega & 8 \\
\hline Atesto realizado sempre após cada trasfega & 8 \\
\hline
\end{tabular}

Fonte: Dados da pesquisa

Os resultados da caracterização do engarrafamento, do arrolhamento e da capsulagem estão indicados na Tabela 9. A metade das cantinas avaliadas utiliza garrafas novas de 750 mL no engarrafamento de seus vinhos. Após capacitação com o SEBRAEES, estes produtores passaram a comprar garrafas novas por intermédio da APRUVIT. As garrafas novas são lavadas e esterilizadas adequadamente nas cantinas. Entretanto, quatro outras cantinas reutilizam as garrafas por "economia de custo e sua pequena produção". Segundo Rosier (1995), o reuso de garrafas pode acarretar gostos e aromas 
diferentes, como a contaminação do vinho, pois os cuidados com a limpeza e higienização devem ser redobrados para este tipo de garrafa. Todas as cantinas (Tabela 9) utilizam garrafas escuras, visando minimizar a ação danosa da luz em vinhos tintos. As quatro cantinas de maior produção utilizam engarrafadeira manual; as de menor produção engarrafam os vinhos manualmente.

Para minimizar a ação danosa da luminosidade sobre a estabilidade (reações oxidativas) dos vinhos tintos, a cor da garrafa deve ser preferencialmente verde ou marrom (GUERRA; BARNABÉ, 2005; GUERRA, 2009). As cantinas utilizam rolhas de cortiça natural com a identificação de sua cantina. As rolhas de cortiça natural são, ainda hoje, a melhor vedação para tampar garrafas de vinho (GUERRA, 2010). O diâmetro das rolhas é maior que o diâmetro da boca da garrafa para permitir uma boa vedação, de modo que necessitam ser comprimidas para a introdução na garrafa (GUERRA, 2009). Todas as cantinas pesquisadas utilizavam cápsula para maior proteção de seus vinhos (Tabela 9). O ideal é que a cápsula seja acrescentada imediatamente após a rolha, protegendo-as de desidratação e do crescimento de fungos (GUERRA; BARNABÉ, 2005).

Tabela 9 - Caracterização do engarrafamento, arrolhamento e capsulagem $(n=8)$

\begin{tabular}{lc}
\hline \multicolumn{1}{c}{ Técnicas enológicas } & Cantinas \\
\hline Garrafas novas & 4 \\
Garrafas escuras & 8 \\
Manual (mangueira, caneca e bombinha) & 4 \\
Engarrafadeira manual com controle de & 4 \\
nível & 8 \\
Manual com arrolhador & 8 \\
Rolha de cortiça & 8 \\
Rolha maior que diâmetro da boca da & \\
garrafa & 8 \\
Utiliza cápsula & \\
\hline
\end{tabular}

Fonte: Dados da pesquisa

De acordo com a Tabela 10, todas as cantinas avaliadas utilizam rótulo e contrarrótulo em seus vinhos. As cantinas não possuem em seus rótulos as seguintes informações: número de registro no Ministério da Agricultura, Pecuária e Abastecimento (MAPA); a expressão “indústria brasileira”, por extenso ou abreviado; e a identificação do lote ou da partida. Por estarem enquadrados como produtores artesanais, as cantinas possuem o registro no Serviço de Inspeção Municipal (SIM). A rotulagem de vinhos e 
derivados da uva e do vinho deve estar de acordo com o Decreto Federal no -8.198 , de 20 de fevereiro de 2014 (BRASIL, 2014). Os rótulos das cantinas não possuem o número de lote, o que seria essencial para o rastreamento do produto no caso da necessidade de qualquer ocorrência com o vinho e, ou, falsificações (CHRISTAKI; TZIA, 2002).

Nenhuma das cantinas pesquisadas realiza as análises físico-químicas do vinho (Tabela 10). Os produtores relatam a dificuldade e o custo elevado de realizar estas análises; entretanto, sabem da importância delas para o controle da qualidade de seus vinhos. As análises laboratoriais previstas na legislação brasileira são os métodos oficiais estabelecidos pelo MAPA (BRASIL, 2005). Estas análises permitem verificar se o vinho está em conformidade com os limites analíticos estabelecidos pela legislação brasileira (BRASIL, 1988; BRASIL, 2004).

Tabela 10 - Caracterização da rotulagem e análise laboratoriais $(n=8)$

\begin{tabular}{lc}
\hline \multicolumn{1}{c}{ Parâmetros } & Cantinas \\
\hline Possui rótulos & 8 \\
São colocados no rótulo informações como: & 8 \\
- Nome do produtor & 8 \\
- Fabricante ou engarrafador & 8 \\
- Endereço & 8 \\
- Nome do produto (marca comercial) & 8 \\
- Conteúdo líquido & 8 \\
- Aditivos empregados & 8 \\
- Graduação alcoólica & - \\
- Lote & - \\
- Análises laboratoriais & \\
\hline
\end{tabular}

Fonte: Dados da pesquisa

Dados da Tabela 11 demonstram que todas as cantinas produzem vinho tinto de mesa; somente uma delas produz vinho espumante. A produção total de bebidas das cantinas é de 101.500 L.ano ${ }^{-1}$. Deste total, 49,5\% são de vinho tinto de mesa; 32,3\% são de fermentado de jabuticaba; $14,8 \%$ são de vinho branco de mesa; e 3,4\% são de espumante.

Tabela 11 - Tipos e volumes de bebidas produzidas $(n=8)$ em 2010 


\begin{tabular}{|c|c|c|}
\hline Cantina & Produção (L.ano ${ }^{-1}$ ) & Bebidas (L) \\
\hline A & 12.000 & Vinho tinto de mesa: 5.000; e Fermentado de jabuticaba: 7.000 \\
\hline B & 47.000 & $\begin{array}{l}\text { Vinho tinto de mesa: 27.000; Vinho branco de mesa: 7.000; e } \\
\text { Fermentado de jabuticaba: } 13.000\end{array}$ \\
\hline $\mathrm{C}$ & 20.000 & $\begin{array}{c}\text { Vinho tinto de mesa: 10.000; Vinho branco de mesa: 5.000; e } \\
\text { Fermentado de jabuticaba: } 5.000\end{array}$ \\
\hline $\mathrm{D}$ & 10.000 & $\begin{array}{l}\text { Vinho tinto de mesa: } 3.500 \text {; Vinho branco de mesa: } 1.500 \text {; e } \\
\text { Fermentado de jabuticaba: } 5.000\end{array}$ \\
\hline $\mathrm{E}$ & 2.000 & Vinho tinto de mesa: 2.000 \\
\hline $\mathrm{F}$ & 5.000 & $\begin{array}{l}\text { Vinho tinto de mesa: } 1.000 \text {; Vinho branco de mesa: } 1.500 ; \text { e } \\
\text { Fermentado de jabuticaba: } 2.500\end{array}$ \\
\hline $\mathrm{G}$ & 500 & Vinho tinto de mesa: 500 \\
\hline $\mathrm{H}$ & 5.000 & $\begin{array}{l}\text { Vinho tinto de mesa: } 1.500 \text {; Espumante de uva tinta: } 1.500 ; \\
\text { Espumante de uva branca: } 2.000\end{array}$ \\
\hline Total & 101.500 & $\begin{array}{l}\text { Vinho tinto de mesa: 50.500; Vinho branco de mesa: } 15.000 \text {; } \\
\text { Espumante: } 3.500 \text {; e Fermentado de jabuticaba: } 32.500\end{array}$ \\
\hline
\end{tabular}

Fonte: Dados da pesquisa

\section{CONCLUSÃO}

As técnicas enológicas empregadas foram adequadas em $80 \%$ dos casos desde o cultivo das uvas até o engarrafamento do vinho nas cantinas avaliadas. Algumas medidas para o aprimoramento da qualidade da produção precisam ser adotadas, quais sejam: aquisição de caixas de polietileno de $20 \mathrm{~kg}$; realização da segunda sulfitagem; utilização de levedura selecionada e enzima; tanque de fermentação de polipropileno ou de aço inox; aquisição de garrafas padronizadas; rotulagem das garrafas, de acordo com o Decreto Federal no 8.198, de 20 de fevereiro de 2014; e a realização de análises físico-químicas e sensoriais nos vinhos produzidos.

\section{AGRADECIMENTOS}

Os autores agradecem à Associação dos Produtores de Uva e Vinho Teresense (APRUVIT); e ao PIQDTec/SETEC/CAPES, pelo apoio financeiro.

\section{REFERÊNCIAS}

AMORIM, D. A.; REGINA, M. de A.; FÁVERO, A. C.; MOTA, R. V.; PEREIRA, G. E. Elaboração de vinho tinto fino. Informe Agropecuário, Belo Horizonte, v.27, n.234, p.65-76, 2006.

BRASIL. Ministério da Agricultura, Pecuária e Abastecimento. Lei no 7.678 , de 8 de 
novembro de 1988. Dispõe sobre a produção, circulação e comercialização do vinho e derivados da uva e do vinho. Diário Oficial [da] Republica Federativa do Brasil. Brasília, DF, 9 nov. 1988.

BRASIL. Ministério da Agricultura, Pecuária e Abastecimento. Lei no 10.970, de 12 de novembro de 2004. Normas referentes à complementação dos padrões de identidade e qualidade do vinho e dos derivados da uva e do vinho. Diário Oficial [da] Republica Federativa do Brasil. Brasília, DF, 16 nov. 2004.

BRASIL. Ministério da Agricultura, Pecuária e Abastecimento. Instrução Normativa $\mathrm{n}^{\mathrm{o}}$ 24 , de 8 de setembro de 2005. Aprova o manual operacional de bebidas e vinagre.

Diário Oficial [da] Republica Federativa do Brasil. Brasília, DF, 20 set. 2005.

BRASIL. Ministério da Agricultura, Pecuária e Abastecimento. Instrução Normativa $n^{\underline{0}}$ 49, de $1^{\circ}$ de novembro de 2011. Estabelece as práticas enológicas lícitas para a elaboração de vinho e mosto de uva e para a uva destinada à industrialização. Diário Oficial [da] Republica Federativa do Brasil. Brasília, DF, 3 nov. 2011.

BRASIL. Ministério da Agricultura, Pecuária e Abastecimento. Decreto no 8.198, de 20 de fevereiro de 2014. Regulamenta a Lei no 7.678, de 8 de novembro de 1988. Dispõe sobre a produção, circulação e comercialização do vinho e derivados da uva e do vinho. Diário Oficial [da] Republica Federativa do Brasil. Brasília, DF, 20 fev. 2014.

CAMARGO, U. A.; MAIA, J. D. G.; RITSCHEL, P. Novas cultivares brasileiras de uva. Bento Gonçalves, RS: Embrapa Uva e Vinho, 2010. 64 p.

CHRISTAKI, T; TZIA, C. Quality and safety assurance in winemaking. Food Control, Guildford, v. 13, p. 503-517, 2002.

GUERRA, C. C.; BARNABÉ, D. Vinho. In: VENTURINI FILHO, W. G. V. Tecnologia de bebidas - matéria-prima, processamento, BPF/APPCC, legislação e mercado. São Paulo: Edgard Blücher, 2005. 505 p.

GUERRA, C. C. Vinho tinto. In: VENTURINI FILHO, W. G. V. Bebidas alcoólicas: ciência e tecnologia. São Paulo: Edgard Blücher, v.1, cap.11. 2010. 492 p.

MOTA, R. V.; REGINA, M. de A.; AMORIM, D. A.; FÁVERO, A. C. Fatores que afetam a maturação e a qualidade da uva para vinificação. Informe Agropecuário, Belo Horizonte, v. 27, n. 234, p. 56-64, 2006.

NIXDORF, S. L.; HERMOSÍN-GUTIÉRREZ, I. Brazilian red wines made from the hybrid grape cultivar Isabel: Phenolic composition and antioxidant capacity. Analytica Chimica Acta, Amsterdam, v.659, p.208-215, 2010.

PROTAS, J. F. da S. CAMRGO, U. A. Vitivinicultura brasileira: panorama setorial de 2010. Brasília, DF: SEBRAE; Bento Gonçalves: IBRAVIN: Embrapa Uva e Vinho, 2011. $110 \mathrm{p}$.

REGINA, M. de A.; FRÁGUAS, J. C.; ALVARENGA, A. B.; SOUZA, C. R.; AMORIM, D. A.; MOTA, R. V.; FÁVERO, A. C. Implantação e manejo do vinhedo para produção de vinhos de qualidade. Informe Agropecuário, Belo Horizonte, v.27, n.234, p.16-31, 2006. 
RIBÉREAU-GAYON, P.; LONVAUD, A.; DONÉCHE, B.; DUBUORDIEU, D. Tratado de Enologia II: Química del vino. 1.ed. Buenos Aires: Ediciones MundiPrensa, 2003.

RIZZON, L. A.; MENEGUZZO, J.; MANFROI, L. Planejamento de uma cantina para elaboração de vinho tinto. Bento Gonçalves: Embrapa Uva e Vinho, 2003. 75 p.

RIZZON, L. A.; MIELE, A. Correção do mosto da uva Isabel com diferentes produtos na Serra Gaúcha. Ciência Rural, Santa Maria, v.35, n.2, p 450-455, 2005.

RIZZON, L. A.; ZANUZ, M. C.; MANFREDINI, S. Como elaborar vinho de qualidade na pequena propriedade. Bento Gonçalves: Embrapa Uva e Vinho, 1996. $36 \mathrm{p}$.

ROSIER, J. P. Manual de elaboração de vinho para pequenas cantinas. 2. ed. Florianópolis: EPAGRI, 1995. 72 p.

TRONCOSO, J. C.; RIQUELME, J. S.; LAURIE, F. G.; ABARCA, J. G. Evaluación de las ventajas relativas de la vendimia mecanizada em Chile central. Agricultura Técnica, Santiago, v.62, n.2, p.310 -320, 2002. 